\title{
ASPECTOS LEGAIS REFERENTES AO CONFORTO ACÚSTICO NAS EDIFICAÇÕES URBANAS
}

\author{
Ana Paula Meneghetti de Freitas ${ }^{1}$ \\ Silviane Meneghetti de Freitas ${ }^{2}$
}

\begin{abstract}
Resumo
O meio ambiente tem sofrido consequiências devido ao progresso que ocasiona problemas na qualidade de vida da população, provoca degradação ambiental e causa diferenças sociais. No ordenamento jurídico brasileiro, existem diplomas legais que fixam padrões de emissão de ruídos e parâmetros para sua avaliação em ambientes e mencionam que as pessoas devem ter assegurado a sua saúde, segurança e sossego. O que deve sempre ser levado em consideração é o direito da pessoa humana, tais como, vida com dignidade, qualidade de vida e saúde pública, física e mental, podendo ser protegido o ser humano em quaisquer condições contra agentes produtores de causas agressoras, que possam importar em danos físicos e psíquicos, como os problemas decorrentes da poluição sonora ambiental. O presente artigo apresenta, inicialmente, questões relativas a Legislação em âmbito federal e municipal. A seguir, apresenta Normas Técnicas da ABNT referentes à acústica e enfatiza a responsabilidade do construtor pela falta de isolamento acústico.
\end{abstract}

Palavras-Chaves: legislação ambiental, conforto acústico e edificações urbanas

\begin{abstract}
The environment has been suffering consequences due to the progress that causes problems in the quality of life of the population, it provokes environmental degradation and it causes social differences. In the Brazilian juridical order, they exist legal diplomas that fasten patterns of emission of noises and parameters for your evaluation in atmospheres and they mention that the people must have assured your health, safety and serenity. What should always be taken in consideration it is the human person's right, such as, life with dignity, life quality and public health, physics and mental, could be protected the human being in any conditions against agents producing of causes aggressors, that can matter in physical and psychic damages, as the current problems of the environmental sound pollution. The present article presents, initially, relative subjects the Legislation in federal and municipal ambit. To proceed, it presents Technical Norms of referring ABNT to the acoustics and it emphasizes the builder's responsibility for the lack of acoustic isolation.
\end{abstract}

Key - Words: environmental legislation, I comfort acoustic and urban constructions

\footnotetext{
${ }^{1}$ Engenheira Civil, mestre em Engenharia Civil pela UFSM - e-mail: anameneghetti@ gmail.com

${ }^{2}$ Advogada, aluna do Mestrado de Integração Latino-Americana (MILA/UFSM)
} 


\section{1- LEGISLAÇÃO SOBRE POLUIÇÃO SONORA EM ÂMBITO FEDERAL}

No que tange ao meio ambiente, a Constituição Federal de 1988 assegura em seu artigo 225:

Art. 225. Todos têm direito ao meio ambiente ecologicamente equilibrado, bem de uso comum do povo e essencial à sadia qualidade de vida, impondo-se ao Poder Público e à coletividade o dever de defende-lo e preserva-lo para as presentes e futuras gerações.

O Conselho Nacional do Meio Ambiente (CONAMA), possuem resoluções relacionadas à questão do ruído. A Resolução $n^{\circ} 001$, de 08 de março de 1990, se refere à emissão de ruídos de quaisquer atividades e sua relação com a saúde e sossego público e remete aos critérios e diretrizes das Normas da ABNT, NBR 10151 e NBR 10152. A Resolução $n^{o}$ 002, de 08 de março de 1990, institui o Programa Nacional de Educação e Controle da Poluição Sonora, o Programa "Silêncio", com os objetivos de:

a) Promover cursos técnicos para capacitar pessoal e controlar os problemas de poluição sonora nos órgãos de meio ambiente estaduais e municipais em todo o país;

b) Divulgar junto à população, através dos meios de comunicação disponíveis, matéria educativa e conscientizadora dos efeitos prejudiciais causados pelo excesso de ruído;

c) Introduzir o tema "poluição sonora" nos cursos secundários da rede oficial e privada de ensino, através de um Programa de Educação Nacional;

d) Incentivar a fabricação e uso de máquinas, motores, equipamentos $e$ dispositivos com menor intensidade de ruído quando de sua utilização na indústria, veículos em geral, construção civil, utilidades domésticas, etc;

e) Incentivar a capacitação de recursos humanos e apoio técnico e logístico dentro da política civil e militar para receber denúncias e tomar providências de combate à poluição sonora urbana em todo o Território Nacional;

f) Estabelecer convênios, contratos e atividades afins com órgãos e entidades que, direta ou indiretamente, possa contribuir para o desenvolvimento do Programa SILENCIO.

E, essa iniciativa, não conseguiu mobilizar os governantes e legisladores estaduais e municipais, responsáveis pelo estabelecimento e implantação dos programas estaduais de educação e controle da poluição sonora.

A Resolução do CONAMA n $n^{\circ} 20$, de 07 de dezembro de 1994, instituiu o "selo ruído", fornecido por laboratórios credenciados pelo INMETRO como forma de indicação do nível de potência sonora, medido em decibel ponderado na curva $A, d B$ (A), de uso obrigatório para aparelhos eletrodomésticos, que venham a ser produzidos, importados e que gerem ruído no seu funcionamento.

A respeito das diretrizes do CONAMA pode-se dispor que: 
As diretrizes do CONAMA, incorporando os valores da NBR 10152, são normas gerais, conforme o art. 24, $\S 1^{\circ}$, da Constituição Federal. Assim, os Estados e Municípios podem suplementar esses valores para exigir mais, isto é, fixar índices menores de decibéis no sentido de aumentar a proteção acústica. Contudo, Estados e Municípios não poderão diminuir os índices de conforto acústico, apontados pela norma federal. (MACHADO, 2000, p. 599 apud CARNEIRO, 2004, p. 7)

No Brasil, não existem normas específicas para vibrações em edificações, como as decorrentes da circulação rodoviária e ferroviária em túneis ou em vias superficiais. Considera-se, no entanto, importante esse tipo de análise, pois as vibrações podem causar: a danificação de estruturas e edificações, particularmente em monumentos ou edifícios antigos; a alteração no funcionamento de equipamentos sensíveis às vibrações; e no bem-estar da população, com prejuízos à saúde e ao rendimento nas atividades laborais. (PAIXÃO \& FREITAS, 2004, p.13)

A lei $n^{\circ} 9.605$ de 12 de fevereiro de 1998, Lei de Crimes Ambientais, no seu artigo 54 afirma que:

Art.54. Causar poluição de qualquer natureza em níveis tais que resultem ou possam resultar em danos à saúde humana, ou que provoquem a mortandade de animais ou a destruição significativa da flora.

Pena - reclusão, de um a quatro anos, e multa:

$\S 1^{\circ}$ Se o crime é culposo:

Pena-detenção, de seis meses a um ano, e multa.

O novo Código Civil de 2002 também contempla artigos referentes ao problema de ruído urbano (nos artigos 1.277 a 1.279).

O ruído perturba o sono, o sossego, ou o bem estar dos vizinhos e caracteriza uso nocivo da propriedade, ainda que inexista a intenção de prejudicar ou incomodar, justificando a aplicação da regra do art. 1277 do Código Civil de 2002, pois o que deve ser considerado é a qualidade de vida e a saúde do ser humano e não a atividade econômica.

Consoante dispõe o artigo 1277 do Código Civil:

Art.1277. O proprietário ou o possuidor de um prédio tem o direito de fazer cessar as interferências prejudiciais à segurança, ao sossego e à saúde das que o habitam, provocadas pela utilização de propriedade vizinha.

Deve-se lembrar que o Código Civil sobrepõe à Legislação Municipal. E seu artigo 1227 dá ao proprietário prejudicado o direito de impedir o mau uso da propriedade. 
O Decreto Lei 3688, de 03 de outubro de 1941, Lei das Contravenções Penais afirma que:

Art.42. Perturbar alguém, o trabalho ou o sossego alheios:

I-com gritaria ou algazarra;

II-exercendo profissão incômoda ou ruidosa, em desacordo com as prescrições legais;

III-abusando de instrumentos sonoros ou sinais acústicos;

IV-provocando ou não procurando impedir barulho produzido por animal de quem tem guarda:

Pena-prisão simples, de 15 (quinze) dias a 3 (três) meses, ou multa.

Art.65. Molestar alguém ou perturbar-lhe a tranqüilidade, por acinte ou por motivo reprovável:

Pena-prisão simples, de 15 (quinze) dias a 2 (dois) anos, ou multa.

Como bem observa Carneiro (2004, p.41), a principal distinção entre a contravenção deferida no artigo 42 e a do artigo 65 é que neste último o agente desempenha a sua conduta com dolo consistente na intenção de molestar ou perturbar a tranquiilidade. No caso desse artigo 65 o agente objetiva perturbar alguém, já no outro, artigo 42, simplesmente os perturba.

A legislação brasileira que trata sobre o trabalhador exposto ao ruído inclui as Normas Regulamentadoras do Ministério do Trabalho, como: NR 7 (Programa de Controle de Saúde Ocupacional), NR 9 (Programa de Prevenção de Riscos Ambientais) e $N R 17$ (Ergonomia) e, destaca-se a NR 15 (Atividades e Operações Insalubres) que, em seu anexo 1, relaciona o tempo máximo de exposição ao nível de ruído. Os dados constantes na Tabela 01 foram retirados da $N R-15$, para melhor exemplificação.

Tabela 01 - Limites de tolerância para ruído contínuo ou intermitente.

\begin{tabular}{cc}
\hline Nível de Ruído - dB (A) & Máxima Exposição Diária Permissível \\
\hline 85 & 8 horas \\
86 & 7 horas \\
87 & 6 horas \\
88 & 5 horas \\
89 & 4 horas e 30 minutos \\
90 & 4 horas \\
95 & 2 horas \\
100 & 1 hora \\
105 & 30 minutos \\
\hline
\end{tabular}

Fonte: - Dados parciais do anexo 1 da NR-15 
Cada município apresenta em seu Código de Posturas um capítulo especial, onde é tratado o tema Sossego Público. Via de regra, tais legislações municipais remetem para as normas NBR 10151 e NBR 10152.

\section{2- LEGISLAÇÃO SOBRE POLUIÇÃO SONORA EM ÂMBITO MUNICIPAL}

A Lei Complementar $n^{o}$ 003/02 de 22 de janeiro de 2002, que dispõe do Código de Posturas de Santa Maria/RS apresenta dois capítulos relativos ao ruído. O Capítulo I é o que fala da moralidade e do sossego público, nos seus artigos 21 a 34 e o Capítulo II fala dos divertimentos públicos, em seus artigos 25 a 52 .

Os seus artigos 21 a 24 afirmam que:

Art.21. É proibido perturbar o bem estar público ou particular com sons ou ruídos de qualquer natureza, produzidos por qualquer forma, que ultrapassem os níveis permitidos para as diferentes zonas e horários.

Art.22. Os níveis de intensidade de sons ou ruídos fixados por essa lei, bem como o equivalente e o método utilizado para a medição e avaliação, obedecerão as recomendações das normas técnicas da ABNT, especialmente as Normas NBR 10.151 e NBR 10.152, ou às que lhe sucederem e outras normas municipais posteriormente estabelecidas.

Art.23. Os níveis de intensidade de sons e ruídos referidos no artigo anterior são os constantes na tabela I, que é parte integrante desta Lei.

a)Diurno-compreendido entre 07h e 19h;

b) Vespertino-compreendido entre $19 \mathrm{~h}$ e $22 \mathrm{~h}$;

c)Noturno-compreendido entre $22 \mathrm{~h}$ e $07 \mathrm{~h}$.

Art.24. As atividades potencialmente causadoras de poluição sonora, definidas em lei, dependem de prévia autorização ambiental, para a obtenção dos alvarás de construção e localização.

Os seus artigos 44, 48 e 50 dispõem que:

Art.44. Não serão fornecidas licenças para a realização de jogos ou diversões públicas, causadoras de perturbação ao sossego público, em locais compreendidos em áreas formadas por um raio de 200 (duzentos) metros de hospitais, casas de saúde ou de repouso, estabelecimentos de ensino, creches $e$ asilos.

Art.48. Nas localizações de estabelecimentos de diversões noturnas e gastronomia, o Poder Público Municipal terá sempre em vistas o sossego e o decoro da população, além do disposto no Plano Diretor.

Art.50. Os estabelecimentos de diversão noturna que funcionarem de portas fechadas com isolamento acústico e funcionários destinados a segurança não terão restrição de horário em seu funcionamento noturno.

$\$ 1^{\circ}$ - os estabelecimentos que não apresentarem as condições citadas no caput do artigo não poderão funcionar no período de 01 (uma) às 05 (cinco) horas da manhã; 
$\S 2^{\circ}$ - não estão sujeitos aos dispostos neste artigo os bares que funcionam no interior de hotéis, flats, clubes, associações e hospitais.

O Código de Posturas de Santa Maria utiliza as siglas: CC-Centro Cívico; ZAZona Agrícola; ZI - Zona industrial (estritamente); ZR1- Zona residencial (estritamente); ZR2- Zona residencial/ comercial; ZR3- Zona residencial/industrial e ZR4- Zona comercial/ industrial.

Os valores máximos para ruído externo são definidos conforme o tipo de ocupação da área. As Tabelas 02 mostra os índices do Código de Posturas de Santa Maria.

Tabela 02- Valores máximos permitidos para ruído externo no Código de Posturas de Santa Maria Nível Critério de Aceitação para Ambientes Externos em $\mathrm{dB}(\mathrm{A})$

SIGLAS: CC-Centro Cívico; ZA-Zona Agrícola;ZI-Zona Industrial (estritamente); ZR1-Zona residencial (estritamente);ZR2-Zona residencial/comercial;ZR3-Zona residencial/industrial; ZR4-Zona Comercial/Industrial

\begin{tabular}{lccc}
\hline ZONAS DE USO & DIURNO & VESPERTINO & NOTURNO \\
\hline ZR1,ZA, CC & 55 & 50 & 45 \\
ZR2 & 60 & 55 & 55 \\
ZR3,ZR4 & 65 & 60 & 55 \\
Z1 & 70 & 60 & 60 \\
\hline
\end{tabular}

Fonte: Código de Posturas de Santa Maria

O Decreto Executivo $n^{\circ} 040$, de 16 de fevereiro de 2005 regulamenta a concessão de Alvarás e o horário de funcionamento de estabelecimentos comerciais de natureza industrial e prestadores de serviço em geral, na cidade de Santa Maria/RS. Segundo este decreto o horário de funcionamento de diversão noturna, além do horário normal, é das 22:00 horas às 01:00 h e o horário de madrugada possibilita o funcionamento da 1:00 às 6:00 h da manhã. A autorização de funcionamento e os horários são determinados pelo Estudo de Impacto de Vizinhança mencionado neste decreto.

O Estatuto da cidade, Lei $n^{\circ}$ 10.257, de 10 de julho de 2001 faz referência ao estudo de impacto de vizinhança. Conforme asseveram os artigos 36 e 37:

Art.36. Lei Municipal definirá os empreendimentos e atividades privadas ou públicas em área urbana que dependerão de elaboração de estudo prévio de impacto de vizinhança (EIV) para obter as licenças ou autorizações de construção, ampliação ou funcionamento a cargo do Poder Público municipal. Art. 37. O EIV será executado de forma a contemplar os efeitos positivos e negativos do empreendimento ou atividade quanto à qualidade de vida da população residente na área e suas proximidades, incluindo a análise no mínimo, das seguintes questões: 
I-adensamento populacional;

II-equipamentos urbanos e comunitários;

III-uso e ocupação do solo;

IV-valorização imobiliária;

$V$-geração de tráfego e demanda de transporte público;

VI-ventilação e iluminação;

VII-paisagem urbana e patrimônio natural e cultural.

Há, ainda na referida cidade dois projetos de Lei que mencionam questões relacionadas ao ruído urbano, a Lei Ambiental Municipal e o Código Ambiental do Município de Santa Maria. A Lei Municipal prevê um capítulo referente à poluição do ar, sonora e visual onde dispõe que "o controle da emissão sonora na cidade visa garantir o sossego e o bem estar público, evitando a perturbação por emissões excessivas ou incômodas de sons de qualquer natureza" e ainda dispõe que "fica proibida a utilização ou funcionamento de qualquer instrumento ou equipamento que produza (...) sons que causem incômodos e distúrbios à comunidade circunvizinha".

Ainda, essa mesma Lei prevê a proibição de carros de sons ou propagandas por meios ruidosos; que os padrões de emissão e os limites máximos, de fontes fixas, serão fixadas pela Secretaria Municipal de Proteção Ambiental e que os equipamentos e técnicas de controle de poluição sonora seguem as Normas da ABNT. Ademais, o projeto de Lei do Código Ambiental do Município prevê um capítulo sobre o controle da emissão de ruídos na cidade.

\section{3- AS NORMAS TÉCNICAS DA ABNT - NBR 10151 E NBR 10152}

As Normas Técnicas da ABNT contemplam diferentes aspectos relativos ao ruído. A NBR 10151/2000 - Acústica - Avaliação do ruído em áreas habitadas, visando o conforto da comunidade - Procedimento, tem a finalidade de fixar "as condições exigíveis para avaliação da aceitabilidade do ruído em comunidades", e especifica um método de medição de ruído, as correções necessárias e um critério para a comparação dos níveis encontrados e estabelecidos.

A NBR 10152 estabelece níveis de referência para os compartimentos das edificações e está em fase de redação da nova versão. A NBR 10152/87, atualmente em vigor, denomina-se Níveis de ruído para conforto acústico.

Os valores fixados pela NBR para avaliação de ruídos em ambientes, com janelas abertas ou fechadas, variam ainda conforme o ruído seja aferido em períodos diurno ou noturno. Para medições realizadas no interior de edificações devem ser 
consideradas correções, sendo de menos $10 \mathrm{~dB}$ (A) para janela aberta e menos $15 \mathrm{~dB}$ (A) para janela fechada. Na tabela 02 são apresentados os padrões fixados pelas normas, NBR 10.151 e $N B R 10.152$ e na tabela 03 são mostrados os níveis de critério para ambientes internos, segundo a NBR 10152.

Tabela 03- Padrões fixados pelas Normas NBR 10151 e NBR 10152, em dB (A).

\begin{tabular}{|c|c|c|c|c|c|c|}
\hline \multirow[t]{3}{*}{ Tipos de áres } & \multicolumn{2}{|c|}{$\begin{array}{c}\text { Ambientes } \\
\text { externos }\end{array}$} & \multicolumn{4}{|c|}{ Ambientes internos } \\
\hline & \multirow[t]{2}{*}{ Diurno } & \multirow[t]{2}{*}{ Noturno } & \multicolumn{2}{|c|}{ Diurno } & \multicolumn{2}{|c|}{ Noturno } \\
\hline & & & $\begin{array}{l}\text { Janela } \\
\text { Aberta }\end{array}$ & $\begin{array}{l}\text { Janela } \\
\text { Fechada }\end{array}$ & $\begin{array}{l}\text { Janela } \\
\text { Aberta }\end{array}$ & $\begin{array}{l}\text { Janela } \\
\text { Fechada }\end{array}$ \\
\hline $\begin{array}{l}\text { Áreas estritamente residencial } \\
\text { urbana ou de } \\
\text { hospitais ou de escolas }\end{array}$ & 50 & 45 & 40 & 35 & 35 & 30 \\
\hline $\begin{array}{l}\text { Áreas mistas, predominantemente } \\
\text { residencial }\end{array}$ & 55 & 50 & 45 & 40 & 40 & 35 \\
\hline $\begin{array}{l}\text { Áreas mistas, com vocação } \\
\text { comercial e } \\
\text { Administrativa }\end{array}$ & 60 & 55 & 50 & 45 & 45 & 40 \\
\hline
\end{tabular}

Fonte: Carneiro, 2004. p. 10

Tabela 04- Valores máximos permitidos para ruído externo na NBR 10151

Nível Critério de Aceitação para Ambientes Externos em dB(A)

\begin{tabular}{lcc}
\hline TIPOS DE ÁREAS & DIURNO & NOTURNO \\
\hline Área de sítios e fazendas & 40 & 35 \\
Área estritamente residencial urbana & 50 & 45 \\
Área mista,predominantemente residencial & 55 & 50 \\
Área mista com vocação comercial & 60 & 55 \\
Área mista com vocação recreacional & 65 & 55 \\
Área predominantemente industrial & 70 & 60 \\
\hline
\end{tabular}

Fonte: NBR 10151

\section{4- RESPONSABILIDADE DO CONSTRUTOR PELA FALTA DE ISOLAMENTO ACÚSTICO DA EDIFICAÇÃO}

Nas construções civis, no Brasil, há um grande descaso referente à questão do isolamento acústico. Inúmeras pessoas pensam que o conforto acústico é algo supérfluo, apenas para o bem estar de locais luxuosos. A grande maioria desconhece os prejuízos que a perturbação sonora provoca. 
Segundo carneiro (2004 p.56):

Na atualidade, diante das normas legais existentes sobre a perturbação sonora, verifica-se que essa situação só se perpetua por conta da inércia de suas vítimas que, ignorando os recursos que o aparelhamento jurídico lhes disponibiliza (...) acabam por imaginar-se equivocadamente impotentes para exigir responsabilidade de quem a tem.

Os construtores, na grande maioria, se preocupam em obedecer a regras de edificação municipais sem levarem em consideração a parte acústica. Mesmo após a obra acabada e dentro de todos os padrões exigidos em Lei municipal se ocorrer uma perturbação sonora, houve uma falha construtiva, isto é, um defeito de construção. Por mais que aos olhos das normas municipais aplicáveis não tenha ocorrido nenhum problema, em âmbito federal, de acordo com o artigo 618 do Código Civil é considerado defeito na obra. Consoante dispõe o artigo:

Art.618. Nos contratos de empreitada de edifícios ou outras construções consideráveis, o empreiteiro de materiais e execução responderá, durante o prazo irredutível de 5 (cinco) anos, pela solidez e segurança do trabalho, assim em razão dos materiais, como do solo.

Também, o artigo 927 do Código Civil impõe que: "aquele que, por ato ilícito, causar dano a outrem, fica obrigado a repará-lo”. Sendo que de acordo com o artigo 186 desse mesmo Código "aquele que, por ação ou omissão voluntária, negligência ou imprudência, violar direito e causar dano a outrem, ainda que exclusivamente moral, comete ato ilícito". E, segundo o artigo 187, "também comete ato ilícito o titular de um direito que, ao exercê-lo, excede manifestamente os limites impostos pelo seu fim econômico e social, pela boa fé ou pelos costumes".

O responsável pela obra deve se responsabilizar pela perfeição da mesma, desde o seu funcionamento, segurança, tais como aspectos estéticos e de conforto. $\mathrm{O}$ comprador tem o direito de receber uma obra conforme o seu valor real, pois existem inúmeras construtoras que vendem apartamentos, ditos "classe A", que não possui qualquer cuidado referente ao conforto térmico-acústico do cliente, vindo a adquirir o imóvel sem usufruir sossego.

Os artigos 615 e 616 do Código Civil é bem claro com relação a obra defeituosa, conforme disposto abaixo:

Art.615. Concluída a obra de acordo com o ajuste, ou o costume do lugar, o dono é obrigado a recebe-lo. Poderá, porém, rejeita-la, se o empreiteiro se afastou das instruções recebidas e dos planos dados, ou das regras técnicas em trabalhos de tal natureza. 
Art.616. No caso da segunda parte do artigo antecedente, pode quem encomendou a obra, em vez de enjeita-la, recebe-la com abatimento no preço.

O defeito devido à falta de isolamento acústico do imóvel consiste em um defeito relativo a segurança, por isso trata-se de uso nocivo da propriedade e, se enquadra no que se refere o art. 618 do Código Civil.

Como o imóvel é considerado um bem de consumo, a responsabilidade, pela reparação de danos causados aos consumidores de edificações está abordado nos artigos 12 a 17 do Código de Defesa do Consumidor, Lei 8078 de 11.09.90.

Segundo Carneiro (2004 p. 67):

A responsabilidade do construtor pelo defeito consistente na falta de isolamento acústico adequado, tanto haverá suporte legal no sistema do Código Civil como norma consumerista, embora existam inúmeras diferenças de tratamento entre ambos, como os prazos de garantia e de prescrição, necessidade ou não de elemento culpa, ônus da prova (...) não sendo poucas divergências doutrinárias e jurisprudenciais a respeito.

Ademais, a falta de isolamento acústico adequado ao provocar desassossego, insalubridade, prejuízos no sono, fadiga mental e ao cliente adquirir um imóvel de padrão elevado, quer algo confortável, pagando alto preço por isso, sendo considerados um dano moral, passível de indenização.

De acordo com o artigo 186 do Código Civil:

Art.186. Aquele que, por ação ou omissão voluntária, negligência ou imprudência, violar direito e causar dano a outrem, ainda que exclusivamente moral, comete ilícito.

Outro ponto importante no caso de uma obra construída sem o isolamento acústico adequado consiste na desvalorização dos imóveis afetados por ruídos incômodos ou insalubres.

\section{5- CONSIDERAÇÕES FINAIS}

A poluição sonora amplia-se rapidamente e, poucas pessoas conhecem os efeitos, muitas vezes irreversíveis, do som em sua saúde. Um número ainda menor está consciente dos riscos a que está exposto e da importância de ter condições mínimas de conforto. (PAIXÃO \& FREITAS, 2004, p.06)

Segundo a Organização Mundial da Saúde - OMS, saúde é o "estado de completo bem-estar físico, mental, social e espiritual" e não apenas a ausência de doenças. A presença de um som em um ambiente pode ser desejável quando auxilia, por 
exemplo, na comunicação, no relaxamento ou no divertimento das pessoas. Entretanto, muitas vezes o som pode ser indesejável sendo simplesmente incômodo ou podendo até causar danos temporários ou irreversíveis na saúde e na audição, sendo chamado, nestes casos, de ruído. A classificação de um som como desagradável é subjetiva e depende das preferências pessoais, de aspectos culturais, da atividade que se desenvolve, do estado de ânimo de quem o escuta e do interesse econômico envolvido (BERISTÁIN, 1998).

Apesar dos avanços tecnológicos, o homem continua como o principal agente na geração da contaminação ruidosa, seja pela necessidade de máquinas e equipamentos, ou simplesmente por aspectos culturais e desinformação. A maioria ignora que apenas três decibéis significam o dobro da energia sonora; que a música (ouvida no carro ou na festa) e o tráfego urbano podem atingir índices comprometedores para a sua saúde. Se os profissionais da saúde conhecerem a influência do som nas pessoas, rapidamente poderão identificar os problemas, otimizando o tempo, o custo e o resultado do processo de tratamento.

A construção civil ainda executa imóveis acusticamente inadequados, pois não são disponibilizadas informações, sobre o desempenho acústico das edificações e seus componentes. Os profissionais estão, geralmente, despreparados nesse domínio científico e os clientes ainda não desenvolveram um padrão de exigência para conforto acústico.

A Associação Brasileira de Normas Técnicas (ABNT), a partir do Comitê Brasileiro da Construção Civil e sua Comissão de Estudos de Conforto Ambiental e Energia em Edificações (CE-02:135.01), está empenhada na elaboração de Normas Técnicas, que contemplem a Acústica nas Edificações. O trabalho da comissão tem sido dificultado, porque poucos dados estão disponíveis, sobre os materiais e técnicas construtivas utilizadas no Brasil. Além disso, não existem levantamentos que apontem requisitos identificados com a diversidade cultural da população brasileira.

A legislação brasileira sobre níveis sonoros ambientais estabelece índices difíceis de serem conseguidos, tendo em vista que: as vias urbanas, em geral, apresentam péssimas condições; a frota de veículos em circulação possui idade avançada e manutenção deficiente; grande parte dos motoristas brasileiros têm maus hábitos. 
Decisões políticas ignoram a poluição sonora, mesmo onde existe uma maior consciência do problema, por isso, a União Européia está procurando, "através de um quadro estratégico mais agressivo, objetivo e contundente, avançar de forma coordenada e eficaz com uma política de proteção sonora no espaço europeu". (BENTO COELHO, 1998, p.18)

Em Porto Alegre, observa-se que a administração municipal tem adotado ações corretivas e preventivas, visando à diminuição da poluição sonora. As corretivas destinam-se as fontes fixas e móveis existentes, enquanto as preventivas ocorrem no "licenciamento ambiental, pela avaliação e exigência de eliminação ou minimização dos impactos sonoros de instalações destas atividades". (SCHIMITT, 2000, p. 398)

Existe um relativo consenso no meio acadêmico, de que a melhoria das condições sonoras ambientais depende, inicialmente, da vontade política de resolver o problema; depois, da existência de equipes técnicas, com profundo conhecimento do tema, dotadas de meios e equipamentos para detectar e resolver os problemas, partindo da caracterização do ruído existente na cidade; da existência de uma legislação eficaz; e, finalmente, da conscientização de que o ruído é evitável se todos contribuírem para isso.(PAIXÃO \&FREITAS, 2004)

É necessário que o tema da contaminação acústica saia do meio acadêmico para o seio da comunidade, através da divulgação, nos veículos de comunicação de massa. Além disso, a participação dos pesquisadores no assessoramento das políticas de planejamento urbano precisa ser considerada, pois auxiliaria na modificação de fatores, que afetam a paisagem acústica do ambiente.(PAIXÃO \& FREITAS, 2004)

A qualidade de vida depende, entre outras coisas, de níveis sonoros mais adequados à natureza física e psico-emocional das pessoas. Portanto, colaborar na melhoria da qualidade de vida das pessoas é dever de cada um, especialmente, aqueles que têm o conhecimento técnico-científico e estão comprometidos com a sociedade na qual estão inseridos.

Acredita-se, no entanto, que apesar da legislação vigente, a questão maior consiste na educação e na informação, que aliadas a disponibilização de ambientes residenciais, de lazer e trabalho confortáveis acusticamente, tornam-se imprescindíveis na conscientização de que o ser humano necessita qualidade de vida, segurança e sossego para, realmente, viver. 


\section{6- REFERÊNCIAS BIBLIOGRÁFICAS}

ASSOCIAÇÃO BRASILEIRA DE NORMAS TÉCNICAS. NBR 10.151: Avaliação do nível do ruído em áreas habitadas visando o conforto da comunidade. Rio de Janeiro: ABNT, 2000. 4p.

ASSOCIAÇÃO BRASILEIRA DE NORMAS TÉCNICAS. NBR 10.152: Níveis de ruído para o conforto acústico. Rio de Janeiro: ABNT, 1987. 7p.

BÁRING, João Gualberto. Desenvolvimento tecnológico em acústica das edificações: conceituação ( $1^{\mathrm{a}}$ e $2^{\mathrm{a}}$ Parte). In: Tecnologia de Edificações /Projeto de Divulgação Tecnológica Lix da Cunha. São Paulo: Pini/IPT, 1988, p. 415 - 460

BENTO COELHO, J. L. Políticas européias sobre ruído ambiente e o espaço ibérico. In: Revista de Acústica e Vibrações, 22. Florianópolis: SOBRAC, 1998, p.18-22.

Brasil. Código Civil. 2002. São Paulo: ed. Editora Revista dos Tribunais, 2002.

BRASIL. Constituição (1988). Constituição da República Federativa do Brasil. Brasília: Centro Gráfico do Senado Federal, 1988. 292p.

BRASIL. Decreto n. 040, de 16 de fevereiro de 2005. Fixa a concessão de alvarás de funcionamento estabelecimentos. Disponível em: <http://www.santamaria.rs.gov.br/>. Acesso em: 09 abril 2005.

BRASIL. Ministério do Trabalho e Emprego.Portaria n. 3214, 8/6/78, NR 15:

Atividades e operações insalubres. Disponível em:

<http://www.mte.gov.br/Temas/SegSau/Legislacao/Normas/Default.asp>.Acesso em: 08 setembro 2003.

BRASIL. Lei Orgânica do Município de 1995. Da moralidade e do Sossego Público. Código de Posturas, Município de Santa Maria-RS, 1995.

BRASIL. Lei ${ }^{\circ}$ 9.605, de 12 de fevereiro de 1998. Lei de Crimes Ambientais, São Paulo: ed. Editora dos Tribunais, 2002.

BRASIL. Decreto-Lei 3688, de 03 de outubro de 1941. Lei das Contravenções Penais, São Paulo: ed. Editora dos Tribunais, 2002.

BRASIL. Lei $\mathrm{n}^{\circ}$ 9.605, de 12 de fevereiro de 1998. Lei de Crimes Ambientais, São Paulo: ed. Editora dos Tribunais, 2002.

BRASIL. Ministério do Meio Ambiente. Comissão Nacional do Meio Ambiente. Resolução CONAMA n. 001, de 08 de março de 1990. Disponível em: <http://www.mma.gov.br/port/conama/index.html>. Acesso em: 26 agosto 2003.

BRASIL. Ministério do Meio Ambiente. Comissão Nacional do Meio Ambiente. Resolução CONAMA n. 002, de 8 de março de 1990. Disponível em: <http://www.mma.gov.br/port/conama/index.html>. Acesso em: 26 agosto 2003.

BRASIL. Ministério do Trabalho e Emprego.Portaria n. 3214, 8/6/78, NR 15:

Atividades e operações insalubres. Disponível em: 
<http://www.mte.gov.br/Temas/SegSau/Legislacao/Normas/Default.a p >. Acesso em: 08 setembro 2003.

CARNEIRO, W. A. M., 2004. Perturbações Sonoras nas Edificações Urbanas: ruído em edifícios, direito de vizinhança, responsabilidade do construtor, indenização: doutrina, jurisprudência e legislação, 3. ed., atual e ampl: Editora dos Tribunais. São Paulo, 2004, 330p.

GERGES, S. N.Y. Ruído: Fundamentos e Controle. 2. ed. Florianópolis: NR Editora, 2000. 676p.

PAIXÃO, D.X.; FREITAS, A.P.M. A Acústica e o Desenvolvimento Sustentável.In: Santa Maria: Simpósio Internacional Fronteiras na América Latina, 2004. Anais... Santa Maria: UFSM, 2004.

SCHIMITT, Nara I. M. et alii. Gestão ambiental no controle da poluição sonora: a experiência de Porto Alegre. In: XIX Encontro da Sociedade Brasileira de Acústica. Belo Horizonte, 2000, p. 398 - 403. 